\title{
139 \\ Teaching HCI and Design of Interactive Systems
}

\author{
Peter Gorny \\ University of Oldenburg, \\ Oldenburg, Germany \\ Gorny@informatik.uni-oldenburg.de \\ http:=//www-cg-hci.informatik.uni- \\ oldenburg.de
}

\author{
Thomas T. Hewett \\ Drexel University, \\ Philadelphia, PA, USA \\ HEWETT@duvm.ocs.drexel.edu \\ http://duvm.ocs.drexel.edu/ hewett/
}

IFIP Working Group 13.1 (Education in HCI and HCI Curriculum) continues discussion about how to organize the qualification process for $\mathrm{HCI}$ in Higher Education. In several workshops that have taken place at other conferences, and in a recent IFIP Workshop on Teaching Design of Interactive Systems, the aim has been to explore issues and enhance the integration of $\mathrm{HCI}$ education in the curricula of different disciplines such as Computer Science, Psychology, Graphics Design and, because of the growing use of embedded computer systems in all kinds of devices, Industrial Design.

In the conference workshop on Education in $\mathrm{HCI}$ : Transcending Disciplinary and National Boundaries held at INTERACT'90, the initial discussions quickly revealed that the structure of a university education in each of the countries represented at the workshop was different enough that discussing curricula within these structures was relatively difficult and that there was a strong need to establish a common terminology. The workshop participants also discovered that the different educational structures had a major impact on the ability to cross disciplinary boundaries, a necessity for the field of HCI. After the workshop participants had laid out the different structures of education, they identified the professional categories which students were being educated and trained to fill. These categories were: The Researcher, The Professionally Oriented Researcher, The Research Oriented Professional, and The Professional. In this workshop there was both strong and profound agreement on the categories, even though the academicpaths leading to them were different (Mantei, Hewett, Eason \& Preece, 1991). 
In the conference workshop on Advances in Teaching the HCI Design Process, held over 2 days at INTERCHI 93, the emphasis was upon presentation of and practice with $\mathrm{HCI}$ design concepts, with four presentations by guest speakers articulating a variety of views. One of the important results of this workshop was a recognition on the part of many participants that tension and uncertainty are both a natural and a healthy part of teaching $\mathrm{HCI}$ design. Arising from different teaching approaches, different disciplines, different emphases on design product and design process, and different teaching philosophies, the underlying tensions and uncertainties in teaching HCI design can be used to improve the teachinglearning environment for both student and teacher (Gasen, Preece, Gorny, \& Hewett, 1994).

In the IFIP Workshop on Teaching Design of Interactive Systems, held over 3 working days in Shaerding, Austria in May of 1997, the initial emphasis was on attempting to engage the participants in developing a common vision of the ideal way to teach design of interactive systems. The goal was to try to break free of the constraints imposed by different working environments, disciplines and organizational burdens to envision the future of teaching HCI Design. The follow up discussions were focused on attempting to use the common vision to derive recommendations for various educational settings. Preparation of a report on the position papers, the conclusions and recommendations, and the other results of this workshop is in progress.
In the conference workshop Teaching $\mathrm{HCI}$ and Design of Interactive Systems, held at INTERACT 97, the issue of integration of $\mathrm{HCI}$ education in the curricula of different countries and disciplines is revisited with participants from countries not represented in earlier workshops. The discussion is intended to focus in part on comparison of present approaches in different countries and subject areas. The expected result is a set of outlines for recommendations to serve as the basis for further development of $\mathrm{HCI}$ related education after the workshop.

\section{References}

Gasen, J. B., Preece, J., Gorny, P., \& Hewett, T. (1994). Advances in Teaching the HCI Design Process. ACM SIGCHI Bulletin, 26 (1), 9-12.

Mantei, M., Hewett, T., Eason, K. \& Preece, J. (1991). Report on the INTERACT '90 Workshop on Education in HCI: Transcending disciplinary and national boundaries. Interacting with Computers, 3, 232-240. 